\title{
DUKUNGAN ORANG TUA DAPAT MENINGKATKAN PRESTASI SISWA BOARDING SCHOOL DI MI MAMBAUL ULUM POWAK TLONTO RAJA PASEAN PAMEKASAN
}

\author{
Endang Fauziyah. S, Abdan Syakura, dan Dinar Vincy Y.B \\ Politeknik Negeri Madura, Politeknik Negeri Madura, dan Universitas Islam Madura \\ Email: endangfauziyah.nawawi@gmail.com, syakuraa33@gmail.com,dan \\ dinarvincy89@gmail.com
}

\begin{abstract}
Abstrak
Masih banyak orang tua yang belum mengetahui perkembangan model sekolah untuk siswa dengan tingkatan sekolah dasar. Hal ini dipengaruhi oleh beberapa faktor antara lain kurangnya pengetahuan orang tua karena kurangnya informasi atau akibat minimnya sosialisasi tentang model pendidikan dasar yang ada dan diakui secara formal oleh pemerintah. Penelitian ini menggunakan desain studi analitik corelatif cross sectional, untuk menguji hubungan dukungan orang tua dengan prestasi siswa boarding school. Hasil penelitian kedua variabel kemudian diuji statistik menggunakan SPSS Rank Spearman. Pada penelitian ini populasinya adalah orang tua siswa SDI Mambaul Ulum kelas 4-6 sebanyak 34 orang. Hasil uji statistik menggunakan Rank Spearman memnunjukkan hasil sig-2 tailed sebesar $0.001<0.05$, artinya hipotesis diterima. Hal ini menunjukkan bahwa ada hubungan antara dukungan orang tua dengan prestasi siswa boarding school di MI. Mambaul Ulum Powak Tlonto Raja Kec. Pasean Kabupaten Pamekasan. Peningkatan prestasi siswa dapat meningkatkan harapan kesejahteraan di masa yang akan datang, siswa merupakan generasi penerus yang akan menjalankan tongkat estafet bagi kepentingan bangsa khususnya wilayah tempat tinggalnya, untuk itu diperlukan dukungan orang tua terus menerus guna mewujudkan hal tersebut.
\end{abstract}

Kata Kunci: prestasi siswa, dukungan orang tua, boarding school

\begin{abstract}
There are many parents who still didn't know about the development of school model for children with elementary school levels. This condition clarified by the lack of socialization from government relate with the role of model in elementary. Research design that is use in this research is correlative cross sectional analytical study. Analytical design is research design that testing the correlation between variables which aims to find a relationship of parental support and students achievement. The result of both variables tested by SPSS Rank Spearman. The population in this research is student's family of MI Mambaul Ulum from 4-6 grade as many as 34 people. The result showed that sig 2 tailed is 0,001 $<0,05$ so the hypothesis is accepted. It means that there is a correlation between parental support with students achievement at Mambaul Ulum boarding school Tlonto Raja Pasean sub-district, Pamekasan regency. The improving of children's achievement can increase prosperity in future, children are the next generation who will carry out the interests of nation especially for their area where their live.
\end{abstract}

Keyword: student achievement, parental support, boarding school 


\section{PENDAHULUAN}

Adanya globalisasi dan perubahan tuntutan masyarakat menyebabkan madrasah harus berbenah melakukan perubahandan pembaharuan organisasi agar eksistensinya tetap terjaga bahkan mampu bersaing dengan sekolah umum khususnya. Madrasah, dalam konteks mempersiapkan peserta didik menghadapi perubahan zaman akibat globalisasi ini memiliki peran yang amat penting. Diantaranya madrasah harus berhasil dalam menyiapkan peserta didik untuk menghadapai tantangan masa depan yang lebih kompleks akan menghasilkan lulusan yang memiliki keunggulan kompetitif dan menjadi pemimpin umat, pemimpin bangsa yang ikut menentukan arah perkembangan bangsa ini. Madrasah juga harus mampu berkarya khususnya prestasi bagi para siswanya ${ }^{1}$

Salah satu karya yang dapat dikembangkan madrasah adalah adanya program boarding school. Nama lain dari istilah boarding school adalah sekolah berasrama. Para murid mengikuti pendidikan reguler dari pagi hingga siang di sekolah kemudian dilanjutkan dengan pendidikan agama atau pendidikan nilai-nilai khusus di sore dan malam hari. Selama 24 jam anak didik berada di bawah pendidikan dan pengawasan para guru pembimbing. Kenyataan yang ada di lapangan menunjukkan bahwa masih banyak orang tua yang belum mengetahui perkembangan model sekolah untuk anak dengan tingkatan sekolah dasar.

Sampai dengan saat ini masih ada sebagian orang tua yang tidak memperhatikan pendidikan bagi anak. Menurut laporan tahun 2017 di Indonesia masih terdapat sekitar 1,37 juta anak usia 7-15 tahun yang tidak bersekolah (UNICEF, 2018). Propinsi Jawa Tengah, Jawa Timur, dan Jawa Barat terdapat sekitar 42\% anak-anak yang putus sekolah. Putus sekolah menjadi masalah yang cukup serius karena ironis dengan usaha pemerintah yang gencar untuk memajukan pendidikan nasional. Putus sekolah merupakan jurang yang menghambat anak untuk mendapatkan haknya. Putus sekolah disebabkan oleh berbagai faktor. Faktor ekonomi, psikologis, serta lingkungan sosial menjadi pemicu seorang anak tidak dapat melanjutkan pendidikannya.

Kehidupan di asrama (pondok pesantren atau sejenisnya) tentu berbeda dengan kehidupan sebelumnya ketika masih tinggal di rumah, sehingga untuk bisa mencapai tujuan yang telah disebutkan diatas, setiap anak harus bisa melakukan penyesuaian diri agar bisa bertahan hingga menyelesaikan pendidikannya di sekolah berasrama tersebut. Masalah yang muncul adalah adanya siswa yang tidak mampu melakukan penyesuaian diri dengan baik untuk mengikuti sistem kehidupan di asrama, seperti anak yang terbiasa dimanja yang keperluannya selalu dilayani akan mengalami banyak kesulitan dalam penyesuaian diri. Anak yang terbiasa dituruti keinginan-keinginannya, biasanya sulit menerima situasi yang berbeda dengan keinginannya itu, seperti menu makanan yang tidak sama dengan seleranya, mandi harus antri, dan lain-lain. Selain itu anak yang terbiasa hidup bebas cenderung sulit untuk disiplin dan mentaati aturan yang ada di asrama, sehingga sering melakukan pelanggaran. Kesulitan dalam penyesuaian diri akan

\footnotetext{
${ }^{1}$ Nurhadi, Ali. "Perubahan Organisasi Bagi Pengelola Madrasah Dalam Menghadapi Persaingan Global." AL-FIKRAH: Jurnal Studi Ilmu Pendidikan dan Keislaman 1.1 (2018): 16-27.
} 
menimbulkan masalah-masalah baru, seperti anak merasa tertekan, stress, prestasi belajar menurun, melanggar peraturan asrama, membuat gaduh, berbuat onar, dan lain-lain ${ }^{2}$

Orang tua bisa mendampingi anak dalam memberikan pengertian dan pemahaman kepada anak dalam pemilihan jenis sekolah. Ketika memasuki kelompok sosial yang baru, individu akan menghadapi teman-teman yang asing bagi mereka serta aturan kelompok yang mungkin sama sekali berbeda dengan kelompok yang dikenal sebelumnya. Pada kondisi seperti ini dapat dilihat bagaimana usaha individu mempelajari aturan-aturan baru itu dan kemampuan untuk melibatkan diri dalam kelompok, sehingga akhirnya individu dapat menyesuaikan diri dan memasuki kelompok tersebut dengan baik.

Dukungan orang tua pada program boarding school sangat diharapkan. Hal ini disebabkan boarding school membutuhkan biaya yang lebih besar dibandingkan dengan program non boarding school. Biaya ini digunakan untuk pelaksanaan berbagai program yang sudah direncanakan. Keberhasilan program boarding school sangat bergantung pada peran orang tua.

Madrasah merupakan lembaga formal yang bernuansa keislaman dan juga memuat kurikulum K-13. Selain sama dengan lembaga pendidikan umum seperti SD, SMP dan SMA. Sebagai lembaga pendidikan Islam madrasah mempunyai peran dan tugas dalam meralisasikan cita-cita umat Islam yang telah menjadi tujuan mereka untuk dididik manjadi individu yang beriman dan bertaqwa serta mempunyai pengetahuan. Madrasah adalah pendidikan Islam yang mempunyai pengaruh pada penerus bangsa yang bersistem nilai dan kepercayaan, pengetahuan dan norma serta tradisi dalam berbagai perilaku tradisional yang telah membudaya terhadap satu penerus ke penerus selanjutnya. ${ }^{3}$

MI Mambaul Ulum Powak Tlonto Raja Pasean Pamekasan sebagai salah satu madrasah yang menerapkan program boarding school. Program ini lahir disebabkan keinginan masyarakat untuk menyekolahkan pada putra putrinya dengan waktu yang penuh dengan harapan tidak terpengaruh lingkungan yang kurang mendukung pada perkembangan baik intelektual khususnya pada sikap dan etika serta nilai-nilai religius.

Berdasarkan hal inilah akan dilakukan penelitian dengan tujuan untuk mengetahui hubungan dukungan orang tua dengan prestasi siswa boarding school di MI. Mambaul Ulum Powak Tlonto Raja Kecamatan Pasean Kabupaten Pamekasan, sehingga dipilihlah judul Dukungan Orang Tua Dapat Meningkatkan Prestasi Siswa Boarding School di MI Mambaul Ulum Powak Tlonto Raja Pasean Pamekasan.

\section{METODE PENELITIAN}

Pendekatan yang digunakan dalam penelitian ini, yaitu menggunakan pendekatan kuantitatif (quantative research). Pada penelitian ini populasinya adalah orang tua yang memiliki anak siswa MI Mambaul Ulum kelas 4-6 sebanyak 34 orang dengan menggunakan teknik sampling total populasi.

Metode pengumpulan data dengan menggunakan angket dan dipilih sangat efektif untuk pengumpulan data dalam penelitian kuantitatif. Analisis data yang digunakan

\footnotetext{
${ }^{2}$ Nurhadi, Ali, and Atiqullah Atiqullah. "Manajemen Pemasaran Pendidikan Kelas Internasional di Pesantren." (2020).

${ }^{3}$ Ida Rochmawati, "Optimalisasi Peran Madrasah dalam Pengembangan Sistem Nilai Masyarakat.” Jurnal Padagogia, Vol. 1. No. 2 (Juni 2012).163-164.
} 
menyeseuaikan desain penelitian yang direncanakan, yaitu korelasi. Desain yang digunakan dalam penelitian ini adalah desain studi analitik corelatif cross sectional ${ }^{4}$.

Desain analitik merupakan desain penelitian yang menguji hubungan antar variabel yang bertujuan untuk menemukan hubungan variabel dependen dan variabel independen yaitu hubungan antara variabel dukungan orang tua dengan prestasi siswa boarding school. Cross sectional artinya data diambil dalam satu kali waktu. Hasil penelitian kedua variabel kemudian diuji statistik menggunakan SPSS Rank Spearman.

\section{HASIL PENELITIAN}

MI Mambaul Ulum Powak Tlonto Raja Kecamatan Pasean Kabupaten Pamekasan dalam menyelengarakan kegiatan pendidikan menggunakan kurikulum terpadu, perpaduan antara kurikulum pemerintah melalui kementrian agama dan kurikulum pesantren, mengingat lembaga pendidikan ini bernaung di bawah kementrian agama dan pondok pesantren, sehingga tercermin dalam visi, misi dan tujuan perpaduan kurikulum tersebut yang menjadi pondasi dasar penyelenggaraan pendidikan di lembaga ini.

Berdasarkan pelaksanaan penelitian tentang dukungan orang tua dapat meningkatkan prestasi siswa boarding school di MI Mambaul Ulum Powak Tlonto Raja Pasean Pamekasan dideskripsikan data kuantitatif dalam bentuk tabel seperti berikut ini.

\section{Distribusi Frekuensi Responden Berdasarkan Usia}

Distribusi frekuensi responden, yaitu orang tua siswa atau wali yang menyekelohkan putra putrinya seperti dalam Tabel 1 berikut ini.

\section{Tabel 1 Distribusi Frekuensi Responden Berdasarkan Usia Orang Tua Siswa di} MI Mambaul Ulum

\begin{tabular}{cccc}
\hline No & Umur & f & Prosentase (\%) \\
\hline 1 & 21-29 Tahun & 0 & $0 \%$ \\
\hline 2 & 30-39 Tahun & 27 & $79 \%$ \\
\hline 3 & 40-59 Tahun & 7 & $21 \%$ \\
\hline \multicolumn{2}{r}{ Sumber: Data primer, 2019 } & 34 & $100 \%$ \\
\hline
\end{tabular}

Sumber: Data primer, 2019

Tabel 1 menunjukan bahwa sebagian besar responden (79\%) berusia diantara 30-39 Tahun, dan tidak satupun responden berusia di antara 21-29 tahun. Artinya orang tua siswa atau wali memiliki usia di atas 30 tahun.

\section{Distribusi Frekuensi Responden Berdasarkan Jenis Kelamin}

Berikutnya didistribusikan responden berdasarkan jenis kelamin baik laki-laki mapun perempuan. Jenis kelamin juga bisa menjadi pengaruh peran orang tuanya. Adapun deskripsinya seperti dalam Tabel 2 berikut ini.

\footnotetext{
${ }^{4}$ Sugiyono. Metode Penelitian kuantitatif, kualitatif dan R\&D. 2009.
} 
Tabel 2 Distribusi Frekuensi Responden Berdasarkan Jenis Kelamin

\begin{tabular}{cccc}
\hline No & Jenis Kelamin & Frekuensi & Persentase (\%) \\
\hline 1 & Laki-Laki & 22 & $65 \%$ \\
\hline 2 & Perempuan & 12 & $35 \%$ \\
\hline & Total & 34 & $100 \%$ \\
\hline
\end{tabular}

Sumber: Data primer, 2019

Berdasarkan Tabel 2 menunjukkan sebagian besar responden (65\%) berjenis kelamin laki-laki, dan sebagian kecil responden (35\%) berjenis kelamin perempuan. Artinya dominasi laki-laki bila dibandingkan dengan perempuan.

\section{Distribusi Frekuensi Responden Berdasarkan Pekerjaan.}

Berikutnya didistribusikan responden berdasarkan pekerjaan. Jenis pekerjaan dari orang tua atau wali responden juga bisa menjadi pengaruh peran orang tuanya. Adapun deskripsinya seperti dalam Tabel 3 berikut ini.

\section{Tabel 3 Distribusi Frekuensi Responden Berdasarkan Pekerjaan}

\begin{tabular}{clccc}
\hline No & & Pekerjaan & Frekuensi & Prosentase (\%) \\
\hline 1 & Tidak bekerja & 3 & $9 \%$ \\
\hline 2 & Wirausaha & 26 & $76 \%$ \\
\hline 3 & Swasta & 5 & $15 \%$ \\
\hline 4 & TNI/ABRI & 0 & $0 \%$ \\
\hline 5 & PNS & 0 & $0 \%$ \\
\hline & & Total & 34 & $100 \%$ \\
\hline
\end{tabular}

Sumber: Data primer, 2019

Berdasarkan Tabel 3 menunjukan sebagian besar responden (76\%) bekerja sebagai wirausaha, dan tidak satupun responden yang bekerja sebagai PNS dan TNI/ POLRI. Posisi MI Mambaul Ulum Powak Tlonto Raja Kecamatan Pasean Kabupaten Pamekasan berada di wilayah utara Kabupaten Pamekasan berbatasan dengan daerah pantai utara Madura sehingga daerah pesisir. Banyak masyarakat di daerah ini yang berwirausaha karena lahan pertanian juga mengandalkan air hujan. Daerahnya berkapur.

\section{Distribusi Frekuensi Responden Berdasarkan Pendidikan}

Berikutnya didistribusikan responden berdasarkan tingkat pendidikan. dari orang tua atau wali responden juga bisa menjadi pengaruh perannya. Adapun deskripsinya seperti dalam Tabel 4 berikut ini.

\section{Tabel 4 Distribusi Frekuensi Responden Berdasarkan Pendidikan}

\begin{tabular}{cccc}
\hline No & Pendidikan & Frekuensi & Persentase (\%) \\
\hline 1 & Tidak sekolah & 4 & $12 \%$ \\
\hline
\end{tabular}




\begin{tabular}{clcc}
\hline 2 & Pendidikan dasar (SD/MI) & 22 & $65 \%$ \\
\hline 3 & $\begin{array}{l}\text { Pendidikan Menengah pertama } \\
\text { (SMP/MTs) }\end{array}$ & 7 & $21 \%$ \\
\hline 4 & $\begin{array}{l}\text { Pendidikan Menengah (SMA/ } \\
\text { Sederajat) }\end{array}$ & 1 & $3 \%$ \\
\hline 5 & Pendidikan Tinggi (PT) & 0 & $0 \%$ \\
\hline$\quad$ Total & 34 & $100 \%$ \\
\hline
\end{tabular}

Sumber: Data primer, 2019

Berdasarkan Tabel 4 menunjukan sebagian besar responden (65\%) memiliki pendidikan akhir pendidikan dasar (SD/MI/SMP/MTs), dan tidak satupun responden memiliki pendidikan akhir pendidikan tinggi.

Berdasarkan data dasar yang telah dipaparkan pada point 1 sampai dengtan 4 selanjutnya dideskripsikan secara kuantitatif data khusus hasil penelitian. Data ini meliputi data variabel $\mathrm{X}$ yaitu dukungan orang tua dan data variabel $\mathrm{Y}$ yaitu prestasi belajar. Data itu dideskripsikan berikut ini.

\section{Data Khusus Tentang Dukungan Orang Tua}

Berdasarkan hasil penyebaran data melalui angket yang telah dilakukan uji validitas dan reliabilitasnya selanjutnya diperoleh data tentang dukungan orang tua siswa boarding school di MI Mambaul Ulum Powak Tlonto Raja Kecamatan Pasean Pamekasan seperti dideskripsikan dalam Tabel 5 berikut ini.

Tabel 5 Dukungan Orang Tua Siswa Boarding School di MI. Mambaul Ulum Powak Tlonto Raja Kecamatan Pasean Kabupaten Pamekasan

\begin{tabular}{|c|c|c|c|}
\hline No & Dukungan orang tua & Frekuensi & Persentase $(\%)$ \\
\hline 1 & Baik & 11 & $32 \%$ \\
\hline 2 & Cukup & 21 & $62 \%$ \\
\hline 3 & Kurang & 2 & $6 \%$ \\
\hline & Total & 34 & $100 \%$ \\
\hline
\end{tabular}

Sumber: Data primer, 2019

Tabel 5 menunjukan sebagian besar dukungan orang tua siswa boarding school sebanyak 62\% di MI. Mambaul Ulum Powak Tlonto Raja Kecamatan Pasean Kabupaten Pamekasan dikategorikan cukup dan sebagian kecil $(6 \%)$ memiliki dukungan kurang. Dukungan baik mencapai 11 orang tua atau $32 \%$. Oleh sebab itu dominasi terbesar dukungan orang tua berkategori cukup.

\section{Data Khusus Prestasi Siswa}

Selanjutnya data khusus tentang hasil belajar siswa boarding school di MI Mambaul Ulum Powak Tlonto Raja Kecamatan Pasean Pamekasan seperti dideskripsikan dalam Tabel 6 berikut ini. 
Tabel 6 Prestasi Siswa Boarding School di MI. Mambaul Ulum Powak Tlonto Raja Kecamatan Pasean Kabupaten Pamekasan

\begin{tabular}{|c|c|c|c|}
\hline No & Hasil belajar & Frekuensi & Persentase (\%) \\
\hline 1 & Sangat Memuaskan & 17 & $50 \%$ \\
\hline 2 & Memuaskan & 15 & $44 \%$ \\
\hline 3 & Cukup & 0 & $0 \%$ \\
\hline 4 & Kurang & 2 & $6 \%$ \\
\hline & Total & 34 & $100 \%$ \\
\hline
\end{tabular}

Sumber: Data primer, 2019

Berdasarkan Tabel 6 menunjukan prestasi siswa boarding school di MI. Mambaul Ulum Powak Tlonto Raja Kecamatan Pasean Kabupaten Pamekasan yaitu sebanyak setengah siswa (50\%) memiliki prestasi sangat memuaskan, dan tidak satupun siswa yang memiliki prestasi cukup.

\section{Tabulasi Silang Dan Uji Statistik}

Selanjutnya dilakukan pengujian hipotesis tentang hubungan silang dukungan orang tua dengan prestasi siswa boarding school di MI Mambaul Ulum Powak Tlonto Raja Kecamatan Pasean Kabupaten Pamekasan seperti dalam Tabel 7 berikut ini.

Tabel 7 Tabulasi Silang Dukungan Orang Tua Dengan Prestasi Siswa Boarding School di MI. Mambaul Ulum Powak Tlonto Raja Kecamatan Pasean Kabupaten Pamekasan

\begin{tabular}{ccccccccc}
\hline & \multicolumn{1}{c}{ PRESTASI } & & & Total & $\%$ \\
\cline { 2 - 9 } DUKU & $\begin{array}{c}\text { Sangat } \\
\text { Memu } \\
\text { askan }\end{array}$ & $\%$ & $\begin{array}{c}\text { Memua } \\
\text { skan }\end{array}$ & $\%$ & $\begin{array}{c}\text { Kur } \\
\text { ang }\end{array}$ & $\%$ & & \\
\hline Baik & 9 & $26 \%$ & 2 & $6 \%$ & 0 & $0 \%$ & 11 & $32 \%$ \\
\hline cukup & 8 & $24 \%$ & 13 & $38 \%$ & 0 & $0 \%$ & 21 & $62 \%$ \\
\hline kurang & 0 & $0 \%$ & 0 & $0 \%$ & 2 & $6 \%$ & 2 & $6 \%$ \\
\hline Total & 17 & $50 \%$ & 15 & $44 \%$ & 2 & $6 \%$ & 34 & $100 \%$ \\
\hline Uji Rank Spearman Sig 2 tailed $=0.001$ & $<0.05 ;$ Hipotesis diterima \\
Corellation Coeficient $=1.000=$ Hubungan Sangat Kuat \\
\hline Sumber: Data primer, 2019
\end{tabular}

Tabel 7 Tabulasi silang dukungan orang tua dengan prestasi siswa boarding school di MI. Mambaul Ulum Powak Tlonto Raja Kec. Pasean Kabupaten Pamekasan menunjukkan bahwa dari 11 orang (32\%) yang memiliki dukungan baik, mendapatkan prestasi yang sangat memuaskan sebanyak 9 orang, prestasi memuaskan 2 orang dan tidak satupun yang memiliki prestasi kurang.

Hasil uji statistik menggunakan Rank Spearman menunjukkan hasil sig-2 tailed sebesar $0.001<0.05$ hipotesis diterima. Artinya ada hubungan antara dukungan 
orang tua dengan prestasi siswa boarding school di MI. Mambaul Ulum Powak Tlonto Raja Kecamatan Pasean Kabupaten Pamekasan.

\section{PEMBAHASAN}

Berdasarkan pengujian hipotesis ditemukan bahwa ada hubungan antara dukungan orang tua dengan prestasi siswa boarding school di MI Mambaul Ulum Powak Tlonto Raja Kecamatan Pasean Kabupaten Pamekasan. Hal ini didasarkan proses penghitungan melalui analisis statistik menggunakan Rank Spearman menunjukkan hasil sig-2 tailed sebesar $0.001<0.05$ sehingga hipotesis alternatif diterima dan hipotesis nihil ditolak.

Dukungan orang tua menyebabkan prestasi belajar anaknya juga meningkat. Siswa yang berada dalam lingkungan sosial dan mental yang baik atau suportif maka akan mendukung pencapaian prestasinya. Begitu juga sebaliknya tanpa dukungan orang tua maka prestasi belajar siswa para putra-putrinya juga menurun. Dukungan orang tua mempengaruhi langsung prestasi belajar anaknya.

Hal ini didasarkan pendapat Friedmen yang menyatakan bahwa orang yang berada dalam lingkungan sosial yang supportif umumnya memiliki kondisi yang lebih baik dibandingkan rekannya yang tanpa keuntungan ini. Lebih khususnya, karena dukungan sosial dapat dianggap mengurangi atau menyangga efek serta meningkatkan kesehatan mental individu atau keluarga secara langsung, dukungan sosial adalah strategi penting yang harus ada dalam masa stress bagi keluarga ${ }^{5}$

Dukungan ini akan berperan pada kemajuannya. Jika hal ini terdapat pada keluarga maka keluarga yang harmonis akan menjadi pendorong utama menciptakan situasi yang mendukung prestasi belajar putra-putrinya. Dukungan keluarga sebagai salah satu faktor dari luar yang dapat mempengaruhi prestasi belajar putra-putrinya.

Hal ini sesuai pendapat Solihah, Vira Maratus dkk yang menyatakan bahwa dalam meningkatkan prestasi belajar perlu diperhatikan beberapa faktor yaitu faktor internal dan eksternal. Faktor internal meliputi aspek fisiologis (kondisi kesehatan jasmani), aspek psikologis yang meliputi tingkat kecerdasan, sikap, bakat, minat, dan motivasi. Faktor eksternal merupakan kondisi di sekitar peserta didik yang terdiri atas lingkungan sosial dan non sosial, metode pembelajaran. Lingkungan sosial meliputi lingkungan sekolah (guru, staf, dan teman-teman) dan lingkungan tempat tinggal (keluarga), sedangkan lingkungan non sosial adalah segala fasilitas penunjang yang dimanfaatkan oleh mahasiswa dalam proses belajar. Selain kedua faktor tersebut faktor ekonomi (keuangan) juga mempengaruhi prestasi belajar ${ }^{6}$

Berdasarkan pendapat ini dukungan orang tua akan berpengaruh langsung pada prestasi belajar anaknya. Orang tua yang peduli dan perhatian pada anaknya dalam belajar akan menimbulkan motivasi belajar dan pada akhirnya berdampak pada prestasinya. Begitu juga sebaliknya ketika orang tua tidak memiliki kepedulian dan acuh tak acuh pada pendidikan anaknya juga berpengaruh pada prestasi belajarnya.

\footnotetext{
${ }^{5}$ Friedman, M.M., Bowden, V.R., Jones, E.G. Buku ajar keperawatan keluarga: riset, teori \& praktik. (Penerjemah: Hamid, A.Y.S. et al.). 2010.

${ }^{6}$ Sholihah, Vira Maratus, Mukhamad Zulfikar Lutfi, Asep Sunandar, and Maulana Amirul Adha. 2020. "ANALISIS HUBUNGAN COST EFECTIVENESS MAHASISWA PENGHUNI ASRAMA DENGAN PRESTASI BELAJAR”. Re-JIEM (Research Journal of Islamic Education Management) 3 (1), 1-12. https://doi.org/10.19105/re-jiem.v3i1.3309
} 
Program boarding school sebagai salah satu program layanan di MI Mambaul Ulum Powak Tlonto Raja Kecamatan Pasean Kabupaten Pamekasan. Program ini mengaharuskan siswa belajar dengan penuh waktu artinya sebagian besar waktu digunakan untuk belajar di sekolah. Oleh sebab itu orang tua harus peduli pada putra-dan putrinya yang mengikuti program ini. Harapannya kesiapan mental dan motivasi belajar para siswa yang mengikuti program ini dapat diwujudkan sehingga mendukung keberhasilan tujuan pendidikan yang direncanakan.

Di samping dukungan orang tua faktor dari siswa secara individu berhubungan dengan perilaku, sikap, motivasi juga berperan penting. Hal ini didasarkan pendapat Nurhadi yang menyatakan untuk mencapai kepuasan hasil belajar siswa tidak terlepas dari faktor siswa secara individu, artinya minat dan motivasi untuk belajar sangat dipengaruhi oleh siswa itu sendiri yang mengarah pada perubahan perilaku siswa dalam belajar. Perubahan perilaku tersebut ada yang bersifat positif seperti keinginan untuk belajar, mengikuti kegiatan pembelajaran secara aktif dan melaksanakan setiap tugastugas yang diberikan. Sedangkan perubahan perilaku yang bersifat negatif seperti sering bolos, tidak menyelesaikan tugas yang dibebankan dan tidak aktif dalam kegiatan pembelajaran yang dilakukan ${ }^{7}$.

Berdasarkan hal ini disamping dukungan orang tua perilaku belajar siswa menjadi penentu juga dalam prestasi belajarnya. Meskipun dukungan orang tua besar akan tetapi perilaku yang dimiliki putra atau putrinya negatif maka akan berdampak pula pada prestasi belajarnya.

Pada prinsipnya dukungan orang tua yang lebih pada bidang sosial dan mental memiliki berbagai fungsi. Roth dalam Engram menyatakan dukungan sosial juga dapat berfungsi sebagai strategi pencegahan guna mengurangi stress akibat negatifnya. Sistem dukungan keluarga ini berupa membantu berorientasi tugas sering kali diberikan oleh keluarga besar, teman, dan tetangga. Bantuan dari keluarga besar juga dilakukan dalam bentuk bantuan langsung, termasuk bantuan financial yang terus-menerus dan intermiten, berbelanja, merawat anak, perawatan fisik lansia, melakukan tugas rumah tangga, dan bantuan praktis selama masa krisis ${ }^{8}$

Dukungan sosial keluarga adalah sebuah proses yang terjadi sepanjang masa kehidupan, sifat dan jenis dukungan sosial berbeda-beda dalam berbagai tahap-tahap siklus kehidupan. Namun demikian, dalam semua tahap siklus kehidupan, dukungan sosial keluarga membuat keluarga mampu berfungsi dengan berbagai kepandaian dan akal. Sebagai akibatnya, hal ini dapat meningkatkan kesehatan dan adaptasi keluarga

Wills dalam Friedman menyimpulkan bahwa baik efek penyangga (dukungan sosial menahan efek-efek negatif dari stres terhadap kesehatan) dan efek utama (dukungan sosial secara langsung mempengaruhi akibat-akibat dari kesehatan) yang ditemukan.

\footnotetext{
7 Nurhadi, M.Pd., Dr. Ali, and Dedi Yusup. 2019. "Manajemen Pembelajaran Berbasis Pendekatan Perubahan Perilaku Dalam Meningkatkan Motivasi Belajar Siswa Di Smp Negeri 3 Pademawu Pamekasan". Re-JIEM (Research Journal of Islamic Education Management) 2 (2), 288-304. https://doi.org/10.19105/re-jiem.v2i2.2871.

${ }^{8}$ Engram, B. Rencana asuhan keperawatan medikal-bedah, vol 3. (Penerjemah: Samba, S.). Jakarta: EGC. 1999.
} 
Sesungguhnya efek penyangga dan utama dari dukungan sosial terhadap kesehatan dan kesejahteraan boleh jadi berfungsi bersamaan sehingga saling mendukung ${ }^{9}$.

Hasil uji statistik menggunakan Rank Spearman menunjukkan hasil sig-2 tailed sebesar $0.001<0.05$ artinya hipotesis diterima. Hal ini dapat diartikan bahwa ada hubungan antara dukungan orang tua dengan prestasi siswa boarding school di MI Mambaul Ulum Powak Tlonto Raja Kecamatan Pasean Kabupaten Pamekasan.

Pada dasarnya orang tua yang sudah memberikan kesempatan kepada anaknya untuk memasuki pesantren sudah memberikan dukungan, hanya saja perbedaan dukungan biasanya dirasa anak pada saat sudah menjalani secara langsung keadaan di pondok pesantren itu sendiri. Faktor sifat anak, teman, dan lingkungan sosial, sedikit banyak juga akan mempengaruhi hal tersebut.

Pesantren didirikan oleh para ulama dan kiai dalam rangka memberikan pendidikan keagamaan kepada masyarakat, atau disebut dengan Tafaqquh fi al Diin. Dari waktu ke waktu fungsi ini berjalan sangat dinamis dan berkembang pesat dari pendidikan tradisional menuju modernisasi pendidikan. ${ }^{10}$

Dalam memberikan pengajaran, para kiai mengutamakan akhlak yang baik. Karena tujuan lain dari pengajaran di pondok pesantren adalah membentuk akhlak yang mulia dan mendidik jiwa agar mengetahui tuhannya. Akhlak mulia ini dapat dilihat dari keseharian santri yang mencerminkan sikap takwa, taat, jujur, amanah, dan lain sebagainya. ${ }^{11}$

Mengacu pada tujuan terbentuknya pesantren baik tujuan umum maupun tujuan khusus. Tujuan umum pesantren adalah membimbing peserta didik untuk menjadi manusia yang berkepribadian Islam dengan ilmu agamanya ia sanggup menjadi penyampai ajaran agama Islam dalam masyarakat sekitar melalui ilmu dan amalnya. Sedangkan tujuan khusus pesantren adalah mempersiapkan para santri untuk menjadi orang alim dalam agama yang diajarkan oleh kyai yang bersangkutan serta mengamalkannya dalam masyarakat. Program boarding school pada dasarnya sudah dilakukan lembaga-lembaga yang berada di bawah naungan pesantren.

\section{PENUTUP}

Berdasarkan penelitian yang dilakukan sesuai rumusan masalah disimpulkan bahwa ada hubungan antara dukungan orang tua dengan prestasi siswa boarding school di MI Mambaul Ulum Powak Tlonto Raja Kecamatan Pasean Kabupaten Pamekasan, artinya dukungan orang tua yang positif dapat meningkatkan prestasi siswa sekolah. Hal ini didasarkan proses penghitungan melalui analisis statistik menggunakan Rank Spearman menunjukkan hasil sig- 2 tailed sebesar $0.001<0.05$ sehingga hipotesis alternatif diterima dan hipotesis nihil ditolak.

Berdasarkan temuan penelitian diberikan saran sesuai manfaat dalam penelitian ini diantaranya kepada para orang tua agar terus meningkatkan dukungan pada putra-

\footnotetext{
${ }^{9}$ Ibid 5

${ }^{10}$ Hilmi Qosim Mubah, Manajemen Pesantren Dan Pendidikan Luar Sekolah (Pamekasan: iainmadura press, 2019), 64.

${ }^{11}$ Mubah, 65.
} 
putrinya dalam pendidikannya. Dukungan dapat berupa dukungan fisik dan psikologis. Di samping itu peran yayasan dan peranan pemerintah juga sangat diperlukan untuk mendukung tercapainya tujuan dari pendidikan siswa berasrama.

\section{DAFTAR PUSTAKA}

Engram, B. Rencana Asuhan Keperawatan Medikal-Bedah, Vol 3. (Penerjemah: Samba, S.). Jakarta: EGC, 1999.

Friedman, M.M., Bowden, V.R., Jones, E.G.. Buku Ajar Keperawatan Keluarga: Riset, Teori \& Praktik. (Penerjemah: Hamid, A.Y.S. et al.). Jakarta: EGC. 2010.

Mubah, Hilmi Qosim. Manajemen Pesantren Dan Pendidikan Luar Sekolah. Pamekasan: iainmadura press, 2019.

Nurhadi, Ali. "Perubahan Organisasi Bagi Pengelola Madrasah Dalam Menghadapi Persaingan Global." AL-FIKRAH: Jurnal Studi Ilmu Pendidikan dan Keislaman 1.1 (2018): 16-27.

Nurhadi, Ali, and Atiqullah Atiqullah. "Manajemen Pemasaran Pendidikan Kelas Internasional di Pesantren." (2020).

Nurhadi, Ali, and Dedi Yusup. 2019. "Manajemen Pembelajaran Berbasis Pendekatan Perubahan Perilaku Dalam Meningkatkan Motivasi Belajar Siswa Di Smp Negeri 3 Pademawu Pamekasan”. Re-JIEM (Research Journal of Islamic Education Management) 2 (2), 288-304. https://doi.org/10.19105/re-jiem.v2i2.2871.

Rochmawati, Ida. "Optimalisasi Peran Madrasah dalam Pengembangan Sistem Nilai Masyarakat." Jurnal Padagogia, Vol. 1. No. 2. Juni, 2012.

Sholihah, Vira Maratus, Mukhamad Zulfikar Lutfi, Asep Sunandar, and Maulana Amirul Adha. 2020. "ANALISIS HUBUNGAN COST EFECTIVENESS MAHASISWA PENGHUNI ASRAMA DENGAN PRESTASI BELAJAR". Re-JIEM (Research Journal of Islamic Education Management) 3 (1), 1-12. https://doi.org/10.19105/re-jiem.v3i1.3309

Sugiyono. Metode Penelitian kuantitatif, kualitatif dan R\&D. Bandung: Alfabeta, 2009. 